\title{
PENSAMENTO NARRATIVO E OS HORIZONTES EPISTEMOLÓGICOS DA TEOLOGIA
}

\author{
NARRATIVE THINKING AND THE EPISTEMOLOGICAL \\ HORIZONS OF THEOLOGY
}

\section{Adriani Milli Rodrigues * Matheus Bonifácio de Souza Saldanha **}

\begin{abstract}
RESUMO
Em tempos considerados por muitos como pós-metafísicos, a crítica realizada por vários pensadores que dialogam com a filosofia de Heidegger à ontoteologia tem promovido uma reflexão mais detida acerca dos caminhos epistemológicos da teologia no cenário contemporâneo. Nesse sentido, o presente artigo procura explorar uma alternativa epistemológica para a teologia que não se oriente pelo raciocínio metafísico abstrato, mas pela fértil concretude dos horizontes do pensamento narrativo. Para tanto, este estudo se organiza em três partes principais. A primeira parte procura problematizar brevemente a crítica ao pensamento metafísico em diálogo com Heidegger. A segunda seção trata das possibilidades epistemológicas oferecidas pelo pensamento narrativo, privilegiando as reflexões de Ricoeur. Finalmente, essas possibilidades serão colocadas em uma perspectiva teológica mais ampla, por meio da observação de traços de uma epistemologia narrativa na teologia de Robert Krieg. Em síntese, o artigo sugere que uma articulação epistemológica da teologia que privilegie o pensamento narrativo por meio da polifonia da linguagem bíblica se apresenta como um caminho promissor para se pensar Deus.
\end{abstract}

Palavras-chave: Metafísica. Ontoteologia. Epistemologia Narrativa. Deus

\section{ABSTRACT}

In times regarded by many as post-metaphysical, the critique of several thinkers who dialogue with Heidegger's philosophy against ontotheology has fostered a more careful reflection on the epistemological possibilities for contemporary theology. In this sense, the present article seeks to explore an epistemological alternative for a theology nonmetaphysically oriented, but that is rather defined by the more concrete horizon of narrative thinking. In order to do that, the study is organized in three main parts. First, the article presents a brief overview of the critique of metaphysical thinking in dialogue with Heidegger. Second, the study explores epistemological possibilities of narrative thinking, highlighting Ricoeur's reflections on that. Finally, these possibilities are observed from a wider theological perspective by articulating aspects of narrative epistemology in the theology of Robert Krieg. In short, the article suggests that a theological epistemology that privileges narrative thinking, particularly by focusing on the polyphony of biblical language, is a promising way of thinking about God.

Keywords: Metaphysics. Ontotheology. Narrative Epistemology. God

\footnotetext{
* Doutor em Teologia pela Andrews University (EUA) e mestre em Ciências da Religião pela Universidade Metodista de São Paulo. Atualmente, professor de Teologia Sistemática no Centro Universitário Adventista de São Paulo (UNASP). E-mail: adriani.milli@ unasp.edu.br

** Bacharel em Enfermagem pela Faculdade Adventista da Bahia (FADBA). Atualmente, estudante de Teologia no Centro Universitário Adventista de São Paulo (UNASP). E-mail: saldanha.017@gmail.com
} 


\section{INTRODUÇÃO}

A provocativa afirmação nitzscheana da "morte de Deus", que aparece particularmente nas obras A Gaia Ciência (cf. NIETZSCHE, 2006, p. 129) e Assim Falou Zaratustra (cf. NIETZSCHE, 2014, p. 19), suscita diferentes reações no campo teológico. Interpretando o conceito nitzscheano da “morte de Deus" enquanto afirmação do fim do pensamento metafísico, no sentido da crise da razão moderna, Souza (2008, p. 65) argumenta que "o conflito de Nietzsche não é, exclusivamente, com o Deus cristão, mas com todo tipo de fundamento divino supraterrestre, o que inclui o Deus de Platão e Aristóteles”. Aliás, no julgamento de Nietzsche (1992, p. 8), “o cristianismo é platonismo para o povo”. Na perspectiva do intérprete italiano Giorgio Penzo, a polêmica nitzscheana "com o cristianismo decadente revela-se, no fundo, como consequência lógica da polêmica com a concepção platônica” (PENZO, 2012, p. 29). Penzo (2012, p. 31) chega a declarar que "Nietzsche não mata Deus, mas limita-se a constatar a ausência do divino na cultura de seu tempo, acusando, pelo contrário, por essa ausência e morte, o pensamento metafísico”. Assim, o intérprete italiano assevera que esse conceito de "morte de Deus" é, de fato, uma constatação metafísica que tem o potencial de purificar a verdadeira "face de Deus e, por conseguinte, a fé em Deus" (PENZO, 2012, p. 31).

De acordo com Küng (1981), a proclamação nitzscheana da "morte de Deus" não objetiva descrever a situação espiritual do mundo da modernidade tardia, mas procura conscientizar as pessoas sobre as sérias consequências do fim do pensamento metafísico. O teólogo suíço não crê que os cristãos devam concordar com todos os argumentos da crítica de Nietzsche, visto que o nível de seriedade de suas acusações não conta com uma correspondência à altura de seu conhecimento da história da teologia. Para Küng (1981, p. 404), os ataques de Nietzsche à teologia "são mais

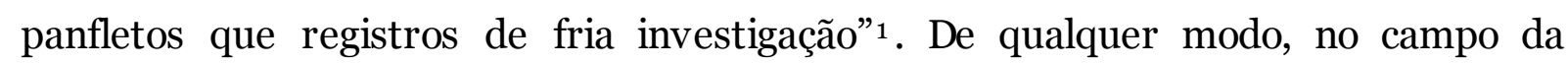
epistemologia, o teólogo suíço reconhece que "Nietzsche perfurou os fundamentos do conhecimento humano e questionou-lhes como ninguém havia feito isso antes" (KÜNG, 1981, p. 410).

\footnotetext{
${ }^{1}$ Todos os textos citados em língua estrangeira seguem tradução livre.
} 
Por um lado, Jürgen Moltmann concorda com a constatação de que o pensamento metafísico platônico exerceu historicamente uma influência negativa sobre a teologia cristã. No entanto, ele argumenta que não faz qualquer sentido expelir "a metafísica da teologia cristã com o auxílio do 'fim da metafísica' proclamado por Nietzsche”, se a teologia não elaborar alguma alternativa em seu lugar (MOLTMANN, 1993, p. 216). De fato, essa problematização oportuniza uma reflexão contemporânea sobre os caminhos epistemológicos da teologia em tempos de crise da razão moderna, na qual há uma forte rejeição à metafísica de matriz platônica.

Nesse contexto, o presente artigo se propõe a discutir uma alternativa epistemológica para a teologia que não se caracterize pelo raciocínio metafísico abstrato, mas pela fértil concretude dos horizontes do pensamento narrativo. Para tanto, este estudo se organiza em três partes principais. A primeira parte procurará problematizar brevemente a crítica ao pensamento metafísico em diálogo com conceitos articulados por Martin Heidegger. Por sua vez, a segunda seção tr atará das possibilidades epistemológicas oferecidas pelo pensamento narrativo, privilegiando as reflexões de Paul Ricoeur. Finalmente, essas possibilidades serão colocadas em uma perspectiva teológica mais ampla, por meio da observação de traços de uma epistemologia narrativa na teologia de Robert Krieg.

Portanto, à luz dessa descrição programática das três seções básicas do presente artigo, o primeiro ponto de discussão é a crítica do pensamento metafísico em diálogo com conceitos heideggerianos.

\section{A CRÍTICA AO PENSAMENTO METAFÍSICO}

A emblemática expressão de uma pretensa "morte de Deus", enquanto crítica ao pensamento metafísico em Nietzsche, encontra seu correspondente em Martin Heidegger na crítica à ontoteologia. De forma mais direta, Heidegger expressa sua crítica ao pensamento metafísico na sua discussão da ontoteologia. Como Leite destaca (2012, p. 91), no pensamento heideggeriano, “a sentença 'Deus está morto!' alude ao destino histórico da metafísica tradicional enquanto onto-teo-lógica.”

Em sua abordagem fenomenológica, Martin Heidegger buscou retornar ao momento “originário" dos fenômenos para, desta forma, se deparar com o fenômeno 
em sua real manifestação. Era de interesse do pensador alcançar o sentido da metafísica, a qual para ele é o fundamento ou a própria natureza do pensamento ocidental. A relação mais explícita entre metafísica e teologia na discussão heideggeriana se circunscreve na noção "da metafísica como ontoteologia" (FRAGOZO, 2010, p. 60).

Heidegger (2011, p. 13) afirma que "o pensamento metafísico é o pensamento que se movimenta no cerne do conceito nesse duplo sentido: indo até a totalidade e transpassando conceptivamente a existência”. Metafísica, enquanto filosofia, possui como tarefa fundamental responder à pergunta pelo ser das coisas, ou seja, responder à pergunta "o que as coisas são?” Para isso, a tarefa metafísica se direciona em um duplo sentido. Para fins didáticos, definiremos estes sentidos como plano horizontal e plano vertical.

No plano horizontal, a metafísica busca definir, em meio às coisas existentes, o que todas elas possuem em comum, aquilo que há de mais essencial nelas. Após determinar a essência de tudo o que existe, a tarefa metafísica se direciona verticalmente à pergunta pela essência suprema, a qual legitima todas as outras. É neste sentido duplo do pensar metafísico que Deus é definido como causa sui, próte arché, ultima ratio (HEIDEGGER, 1973, p. 394). Com isso, podemos dizer que a natureza da metafísica é Ontoteológica (THOMSON, 2000; 2005). Nas palavras de Heidegger (1973, p. 394), "mais objetivamente pensada e determinada de maneira mais clara, a metafísica é: onto-teo-lógica”. Onto, por buscar a essência de todas as coisas; Teo, por buscar a essência suprema, fundamento de todas as outras; e Lógica por estarem estas duas estruturas fundamentadas na razão humana.

De acordo com essa perspectiva metafísica, Deus seria o ser-em-si. Contudo, sua legitimidade é dada pela razão humana que, na busca por conhecer os fundamentos da própria realidade, requer a presença de uma categoria absoluta que ratifique o pensamento metafísico como definitiva interpretação do real. Desta maneira, Deus se transforma em apenas um conceito:

No limite, pode-se dizer: Deus existe somente à medida que o princípio de razão é válido [...] Todo efeito exige, contudo (segundo o princípio de razão) uma causa. Ora, a causa primeira é Deus. Assim o princípio de razão é válido porque Deus existe. Mas Deus somente existe porque o princípio de razão suficiente é válido. A curva se fecha e 'o pensamento transforma-se num círculo'. (HEIDEGGER, 2000, p. $13)$. 
Como causa-sui (causa de si mesmo), a ideia de Deus é apenas um componente necessário para a funcionalidade da razão: a causa-sui não pode ser nada mais que um puro conceito que atua como elemento fundamental para a epistemologia metafísica. "A este Deus não pode o homem nem rezar, nem sacrificar. Diante da causa-sui, não pode o homem nem cair de joelhos por temor" (HEIDEGGER, 1973, p. 399).

Em realidade, o conceito de causa-sui é bastante complexo na discussão da doutrina de Deus na teologia cristã. Tal complexidade parece desafiar a plausibilidade da crítica heideggeriana desse conceito, visto que, em grande medida, a tradição cristã tem rejeitado a categoria causa-sui, por esta denotar uma noção de origem ou causa da realidade divina (ASBILL, 2015). Essa rejeição é enfatizada, por exemplo, por Tomás de Aquino, particularmente em sua obra Suma Contra os Gentios (cf. I.18.5). Ele indica que, para ser a causa de si mesmo, Deus teria que existir antes dele mesmo, algo logicamente impossível (AQUINO, 1990). Para Tomás, Deus é a causa primeira de tudo o que existe, mas ele mesmo é incausado (ELDERS, 1990). Por outro lado, a elaborada articulação filosófica de Deus como causa-sui emerge na filosofia moderna, mais especificamente na reflexão de Renê Descartes. Aliás, Biasoli (2011, p. 10) argumenta que o conceito de Deus como causa sui é central para o "projeto cartesiano de fundamentar a ciência e a metafísica em bases sólidas e indubitáveis”. Em suas Méditations (cf. DESCARTES, 1971-1974, IX, p. 8788), Descartes explica que Deus como causa sui é entendido negativamente, isto é, não há qualquer causa para a sua existência. Positivamente, ele é a causa de si mesmo, na perspectiva de sua infinitude, ou seja, em sua imensidão e incompreensibilidade.

Embora Lee Jr. (2006) desenvolva a ideia de que existem pontos de contato entre a concepção cartesiana de Deus como causa sui e alguns antecedentes conceituais no período medieval, a formulação de Descartes é singular, na medida em que ele busca uma nova concepção de causalidade. Uma explicação detida sobre similaridades e diferenças da afirmação de Deus como causa sui em Descartes e seus predecessores é assunto para outro estudo, mas a percepção dessas diferenças é útil para o seguinte desafio com relação ao pensamento heideggeriano: "se o próprio Heidegger reconhece que só depois de Descartes se pode entender Deus como causa 
sui, como ele pode afirmar que toda a tradição teve essa concepção de Deus?” (LEITE, 2012, p. 65). ${ }^{2}$ Como resposta para essa provocação, Heidegger parece vislumbrar desde Platão e Aristóteles o uso implícito da racionalidade metafísica nos termos de Deus como causa sui. Esse uso foi tematizado de forma mais explícita e elaborada, no entanto, apenas no contexto da filosofia moderna.

Assim, o Deus da onto-teo-logia metafísica, exigido pela razão humana como fundamentação e explicação de toda a realidade, é designado como causa sui (LEITE, 2012). Marion (1995, p. 35) concorda com Heidegger que esse conceito de Deus metafísico encontra sua completa formulação na modernidade (especialmente com Descartes, Espinosa, Leiniz e Hegel) “com o causa sui”, que dá à metafísica uma concepção divina lapidada simplesmente nos termos de "eficiência, de causa e de fundamento".

De fato, no âmbito teológico, a crítica ao pensamento metafísico, expressa em termos da rejeição da ontoteologia, foi acolhida e elaborada por vários estudiosos (cf. WESTPHAL, 2001; AMBROSE, 2016; MARION, 2013; VANHOOZER, 2010; GRENZ, 2005; CANALE, 1987). De fato, muitos deles até propõem uma inversão da ontoteologia para a teo-ontologia (VANHOOZER, 2010; GRENZ, 2005; CANALE, 1987), que, nas palavras de Vanhoozer (2010, p. 104), "escuta em primeiro lugar a autonomeação de Deus no registro bíblico” para inferir aspectos de sua realidade. Vanhoozer (2010, p. 8) define a ontoteologia como "um sistema de pensamento unificado que emprega conceitos tais como o ser supremo ou o movedor imóvel como paliativos conceituais para evitar um regresso metafísico infinito”. Para ele, essa “"má' metafísica" se caracteriza pela imposição de "um sistema de categorias em Deus" (VANHOOZER, 2010, p. 8).

Similarmente, Moltmann (1993, p. 26) constata que "a teologia cristã adotou muito cedo o princípio epistemológico da escola platônica e introduziu o princípio da analogia em sua doutrina do conhecimento de Deus”. Uma das principais críticas de Moltmann (1993, p. 228) ao uso do princípio epistemológico platônico na compreensão de Deus no contexto da história da teologia cristã é o axioma platônico da impassibilidade divina. De fato, o teólogo alemão conclui que uma epistemologia teológica guiada pela ontoteologia não mais se sustenta no labor teológico

\footnotetext{
2 Para uma discussão mais ampla da questão da ontoteologia em autores pré-modernos, veja Marion (2003); Boulnois (2016). Veja também Schrijvers (2010).
} 
contemporâneo (MOLTMANN, 1993, p. 228), e ele vislumbra com otimismo emergentes tendências no pensamento teológico que permitam um novo olhar sobre Deus (MOLTMANN, 1993, p. 200).

Entre as diversas propostas emergentes, destacam-se as possibilidades epistemológicas da teologia no que se refere ao pensamento narrativo, especialmente a partir das reflexões de Paul Ricoeur. Ricoeur também vislumbra, ainda que em seus próprios termos, a superação da ontoteologia e enfatiza os desdobramentos epistemológicos da nomeação de Deus no contexto bíblico. Essa discussão constitui o foco da próxima seção.

\section{POSSIBILIDADES EPISTEMOLÓGICAS DO PENSAMENTO NARRATIVO}

A superação da ontoteologia no pensamento de Paul Ricoeur não é simples de ser descrita. Por isso, antes de indicar os caminhos dessa superação, é necessário reconhecer que o filósofo francês levanta algumas ressalvas à crítica geral da ontoteologia. Ricoeur (2001, p. 363) está consciente de que “o rótulo deliberadamente provocativo de ontoteologia" sofre um "questionamento radical" no pensamento contemporâneo. Mais especificamente, o alvo central de questionamento se refere à identificação, praticada desde a patrística, do Deus da revelação bíblica com o Ser da filosofia grega. Essa identificação, observada particularmente em influentes interpretações tradicionais da nomeação de Deus em Êxodo 3:14 na história da teologia cristã, é vista por muitos teólogos e filósofos atuais como "uma aberração intelectual” (RICOEUR, 2001, p. 374).

O filósofo francês salienta que o questionamento dessa identificação não é algo completamente novo. De fato, Pascal já afirmava uma diferença marcante entre o Deus de Abraão, Isaque e Jacó, e o Deus dos filósofos. Contudo, tal questionamento foi certamente aprofundado na "crítica contemporânea da metafísica", na qual somos confrontados com a ideia de uma “origem não filosófica de Deus e sua nãonecessidade para a filosofia” (RICOEUR, 2001, p. 377). Assim, Ricoeur (2001, p. 377) conclui que o encontro entre Deus e o Ser, "que foi tomado como garantido por Agostinho e, até certo ponto, por Boaventura, Tomás e Duns Scotus, aparece 
espantoso e problemático para o espírito pós-metafísico de nossos contemporâneos”. De acordo com o espírito pós-metafísico de Heidegger, por exemplo, “o autêntico pensamento do Ser exclui a fé cristã, na medida em que ela leva a um Deus que não é o Ser, mas um ser, mesmo que ele se revele o mais elevado. A diferença ontológica, como tema primário, central e final da filosofia, distingue entre Ser e seres, incluindo o ser mais elevado, Deus" (RICOEUR, 2001, p. 377).

Entretanto, a concordância de Ricoeur com Heidegger não elimina suas ressalvas. Para o filósofo francês, a crítica da ontoteologia em Heidegger ignora a perspectiva apofática de Dionísio e aspectos da reflexão do Ser em Tomás de Aquino (RICOEUR, 2001, p. 378). Na visão de Ricoeur (2001, p. 379), em certo sentido, "a genuína ontologia tomista não corresponde ao critério detraído da ontoteologia”. Além disso, o filósofo francês teme que a crítica metafísica contemporânea, particularmente expressa pela rejeição da ontoteologia em Heidegger e da afirmação da morte de Deus em Nietzsche, gera uma marginalização ou regionalização da teologia judaico-cristã no pensamento contemporâneo. $\mathrm{Na}$ opinião de Ricoeur (2001), novas perspectivas teológicas não-metafísicas, como aquelas motivadas pela ética de Levinas e a teologia do amor e do dom em Marion, não oferecem evidências de forte resistência à essa marginalização da teologia. Em contraste, Ricoeur (2001, p. 382) prefere assumir que o Ser pode ser dito de diferentes maneiras, e isso abriria uma porta para sublinhar que as escrituras hebraicas "pensaram o ser de uma maneira nova”.

Isso não significa que Ricoeur deseje retomar o pensamento ontoteológico tradicional. Antes, seu interesse parece se situar na elaboração de uma nova forma de pensar ontologicamente. E esse pensamento está diretamente relacionado com a linguagem, na tentativa de “dizer o ser”. De acordo com Martini (2014, p. 211), Ricoeur procura "pensar a possibilidade da metafísica” na articulação de metáforas. Essa articulação não tem a pretensão de convencer por meio de raciocínios abstratos, mas de enunciar "possíveis aberturas para o que não é possível dizer em totalidade", nas quais, "mediante uma certa forma de dizer, se possa entrever essa totalidade indizível” (MARTINI, 2014, p. 211). Ao passo que Ricoeur evita o termo "metafísica", ele busca refletir sobre uma "ontologia aberta" de forma narrativa (MARTINI, 2014, p. 216), elaborando uma interação "entre as diversas formas de discurso e a ontologia subjacente aos mesmos” (MARTINI, 2014, p. 218). Do ponto de vista epistemológico, 
na medida em que o filósofo francês pressupõe o "ser humano como ser da linguagem", a compreensão é mediada “por signos, símbolos e textos” (MARTINI, 2014, p. 214). Desse modo, a linguagem metafórica expressa a tentativa de "pensar com a palavra" o sentido do ser (MARTINI, 2014, p. 223), uma vez que "o preenchimento da separação ontológica só pode se dar metaforicamente, no sentido do jogo entre velamento e desvelamento" (MARTINI, 2014, p. 222).

Um importante exemplo do pensamento ontológico de Ricoeur por meio da linguagem é o seu interesse "pelas nomeações bíblicas de Deus", que abrange a diversidade de discursos no texto bíblico, com profundidade metafórica e narrativa, ao invés de portar uma metafísica” (SOUZA, 2013, p. 59).3 Como Mettinger (2008) ressalta, na mentalidade semita, nome e realidade caminham juntos. De fato, é particularmente na tarefa da elaboração de uma teologia da nomeação bíblica de Deus que Ricoeur expressa sua tentativa de superação epistemológica da ontoteologia. O filósofo francês fala em "vencer o "saber metafísico" e "desfazer-se de todo saber ontoteológico" (RICOEUR, 1996, p. 189). Para tanto, ele procura elevar o caráter epistemológico do discurso narrativo e evitar a especulação filosófica. Seu lema se resume na expressão "escutar exclui fundar". A tentativa de fundar é o que a metafísica procura fazer por meio de seus enunciados especulativos (por exemplo, Deus como causa primeira), seja de matriz "platônica, aristotélica, kantiana, hegeliana etc." (RICOEUR, 1996, p. 189). É aqui que o sutil "amálgama entre Ser e Deus” da especulação ontoteológica se estabelece (RICOEUR, 1996, p. 189).

Em contraste com a tentativa de fundar está a necessária renúncia contemporânea do saber humano sobre Deus, uma renúncia de "sua vontade de domínio, de suficiência e de autonomia” (RICOEUR, 1996, p. 190). Com a renúncia de fundar, resta a alternativa de escutar a linguagem bíblica sobre Deus, que se caracteriza como uma "linguagem radicalmente não-especulativa" (RICOEUR, 1996, p. 190). Com efeito, a riqueza da linguagem bíblica da nomeação de Deus se define pela multiplicidade, não pela simplicidade, pela polifonia, e não pela monofonia. Como Ricoeur (1996, p. 190) enfatiza, as expressões de nomeação divina na Bíblia “são formas complexas de discurso tão diversas quanto narrações, profecias,

3 Para uma útil apresentação desse tema em Ricoeur, veja Souza (2017, p. 80 -117). 
legislações, provérbios, preces, hinos, fórmulas litúrgicas, escritos sapienciais. Essas formas de discurso nomeiam Deus todas juntas. Mas elas o nomeiam diversamente”.

Dentre esses gêneros textuais específicos, a nomeação de Deus se inicia na Bíblia como nominação narrativa. No drama histórico de uma narrativa de libertação, Deus é "nomeado na terceira pessoa no horizonte do acontecimento contado" (RICOEUR, 1996, p. 192). O foco se encontra na história, no acontecimento. Dizer que Deus é o Deus de Abraão, Isaque e Jacó indica que a compreensão de Deus se reporta à marca dele nos acontecimentos que permeiam a vida desses personagens. De acordo com Ricoeur (1996, p. 191), “é na 'coisa' contada que Deus é nomeado [...] a marca de Deus está na história antes de estar na palavra. A palavra é segunda, na medida em que confessa o traço de Deus no acontecimento”.

Por sua vez, no discurso profético Deus é nomeado enquanto “voz por trás da voz” profética humana. Desse modo, Deus torna-se em última instância “o sujeito absoluto do discurso” (RICOEUR, 1996, p. 192). Ricoeur (1996, p. 192) sugere que, na linguagem bíblica, “o ‘Eu’ profético” é “equilibrado pelo ‘Ele’ narrativo”. Já no gênero de legislação, Deus é nomeado autor da lei no discurso prescritivo da Torá. Nesse caso, Deus é referido na segunda pessoa, no contexto de uma relação entre o indivíduo e Deus estabelecida pela obediência ao mandamento: “Tu amarás o Senhor teu Deus” (RICOEUR, 1996, p. 192). Todavia, deve-se destacar que a instrução legal da Torá se encontra "organicamente vinculada aos eventos fundadores" narrados da libertação de Israel (RICOEUR, 1996, p. 193). Tal "imbricação entre o prescritivo e o narrativo”, observada à luz da aliança entre Deus e seu povo, indica que a concepção moderna de imperativo moral se articula de forma abstrata, ao passo que a prescrição da Torá se expressa de forma concreta no contexto narrativo (RICOEUR, 1996, p. 193).

O discurso bíblico sobre Deus é ainda enriquecido pelo gênero da sabedoria e do hino. Em muitos casos, nesse gênero textual, a nominação de Deus se insere no contexto de uma busca de sentido em meio à ausência dele. Nesses casos, a nominação de Deus tende a ser bem menos pessoal, em comparação com a prescrição legal e a profecia, pois ela se aproxima da incompreensibilidade de Deus, até mesmo seu "silêncio" e “ausência” (RICOEUR, 1996, p. 194). Conforme Ricoeur (1996, p. 194) assevera, "no limite, o discurso da sabedoria encontra um Deus oculto”. Na busca pelo sentido em meio à incompreensão e o silêncio divino, ao contrário do 
oráculo profético e do mandamento, o ser humano não é retratado como "um 'tu' para Deus”, mas “é Deus que se torna um ‘tu’ para o tu humano” (RICOEUR, 1996, p. 194).

A partir desses exemplos, as diferentes formas de discursos acerca de Deus revelam uma maneira polifônica de se pensar sobre ele por meio da linguagem bíblica. Essa polifonia pode ser chamada, de forma ampla, de pensamento narrativo. De forma abrangente, o pensamento narrativo não deve ser confundido com o sentido específico de gênero narrativo, visto que a nomeação de Deus se dá em diferentes tipos de discurso. Antes, o pensamento narrativo se situa no sentido geral de pensamento concreto, em contraste com o pensamento especulativo abstrato. Esse pensamento concreto se relaciona de forma mais direta com a vida em sua estrutura narrativa, por assim dizer. Hahnenberg (2010, p. 163) qualifica a narrativa como "forma básica da vida" e Lucie-Smith (2016, p. 7) considera que a vida humana é “uma corporificação viva de uma história particular”. Aliás, a nomeação de Deus nos gêneros de discurso profético, legislação, sabedoria e hino, conforme destacado acima, apresenta conexões diretas com a narrativa da vida concreta de um povo ou de indivíduos que o buscam. Nesse sentido, essas formas de discurso apresentam uma maneira de pensar narrativa (concreta).

O próprio Ricoeur (1996) utiliza uma definição mais ampla de poética, que não se circunscreve ao sentido específico de gênero textual poético, que se colocaria ao lado de outros gêneros. Antes, ele se refere à nominação de Deus por meio do uso global de todas as formas de discurso sobre Deus encontradas na Bíblia, no sentido de gerar uma compreensão polifônica de Deus e, por conseguinte, do mundo e do próprio ser humano. Nesse sentido amplo da poética, Deus é o referente que coordena os diferentes tipos de discurso, mas ao mesmo tempo lhes escapa. Ou seja, embora essa compreensão polifônica seja válida, ela é ao mesmo tempo incapaz de expressar Deus em sua totalidade.

O mesmo princípio de uso mais abrangente do conceito de poética pode ser aplicado ao conceito amplo de narrativa, para se expressar uma epistemologia mais concreta baseada na linguagem. De fato, Ricouer (2017, p. 285) afirma a importância se "reconstruir a teologia sobre uma base narrativa". O filósofo francês detalha essa possibilidade de empreitada epistemológica na teologia, particularmente à luz de sua crítica à uma teologia abstrata de predominância especulativa. Em suas palavras, “o 
discurso teológico, por conceitual que possa e deva ser, só pode elaborar o horizonte de significação implícito às narrações e símbolos constitutivos das tradições judaica e cristã” (RICOEUR, 2017, p. 285-286). Portanto, ao passo que uma teologia de orientação especulativa basicamente "esvaziaria de seu discurso toda referência às narrativas sobre Israel, Jesus e a Igreja primitiva”, e na melhor das hipóteses procuraria "extrair generalidades sem substância das narrativas relatadas pelas Escrituras", uma teologia de orientação narrativa teria como foco "destacar a inteligibilidade imanente às narrativas contadas" (RICOEUR, 2017, p. 286). Desse modo, ao enfatizar a inteligibilidade narrativa, Ricoeur aponta para uma epistemologia teológica de natureza narrativa.

O último passo dessa reflexão sobre epistemologia teológica será a observação de traços de epistemologia narrativa na teologia de Robert Krieg, que desenvolve sua perspectiva em diálogo com Ricoeur.4 Essa última seção oferecerá vislumbres adicionais dessa possibilidade epistemológica.

\section{TRAÇOS DE EPISTEMOLOGIA NARRATIVA NA TEOLOGIA DE KRIEG}

Embora os escritos do teólogo estadunidense Robert Krieg, professor emérito de teologia sistemática da Universidade de Notre Dame (EUA), não sejam ainda muito explorados no contexto teológico brasileiro, suas reflexões acerca da teologia narrativa são muito úteis para o presente artigo. Um tratamento adequado de suas reflexões certamente exige um estudo específico e amplo da teologia de Krieg, mas ainda assim é possível esboçar aqui alguns traços fundamentais de sua contribuição para uma epistemologia narrativa. O teólogo estadunidense desenvolve suas reflexões em teologia sistemática a partir de uma perspectiva narrativa, incluindo particularmente a doutrina de Deus (KRIEG, 1978), a cristologia (KRIEG, 1988) e a soteriologia (KRIEG, 2013). Em seu diálogo com Ricoeur, Krieg (1988) advoga que o uso teológico de narrativas não representa necessariamente uma redução da teologia ao mero storytelling. Antes, as narrativas têm o potencial de prover imagens e perspectivas que informam e trazem especificidade concreta ao discurso conceitual. Além disso, Krieg (1988, p. 141) salienta a importância de se reconhecer “o caráter

4 Veja, por ex emplo, Krieg (1988, p. 140, 148-154). 
narrativo da existência pessoal”. Isso significa que a vida de uma pessoa é, de fato, uma narrativa em ação.

Nesse sentido, o teólogo de Notre Dame propõe que a narrativa é uma forma privilegiada de se conhecer, com maior detalhamento que o pensamento abstrato, as perfeições pessoais de Deus e a pessoa do Cristo encarnado. Krieg (1988) sublinha que o pensamento ricoeuriano é muito útil para se observar o papel das diferentes narrativas bíblicas no nosso discurso sobre Deus. Mas ele também aprecia o uso narrativo na discussão sobre as perfeições de Deus em Karl Barth. Para Barth (2017, p. 61), a mais fundamental das questões, e, por que não, a essência da teologia cristã, pode ser expressada da seguinte maneira: "Quem e o que é o Deus que se faz conhecido no ponto sobre o qual a Escritura concentra nossa atenção e pensamento?" Portanto, Barth procura trabalhar a concretude do campo conceitual teológico oferecido pelo texto bíblico, onde os atos narrados de Deus orientam as reflexões acerca do divino. Assim, o teólogo suíço parece estimular uma forma de pensamento narrativo: “temos que pensar a partir de eventos definidos e série de eventos [...] segundo o testemunho do Antigo e Novo Testamentos [...] relacionando-os sempre ao dito e atualizado 'Eu sou”' (BARTH, 2017, p. 64).

O maior interesse de Krieg no uso narrativo de Barth se encontra na abordagem barthiana das perfeições de Deus (“A realidade de Deus”, Dogmática da Igreja, II/1). Seguindo uma abordagem narrativa, Barth utiliza narrativas bíblicas das ações divinas para refletir sobre os atributos de Deus. A apreciação de Krieg para com essa abordagem se explica por sua convicção de que o significado de um ato só pode ser devidamente compreendido quando ele é visto dentro de um contexto situacional que se relaciona com outros eventos. É precisamente esse contexto que nos fornece "uma descrição do agente, seu ato e sua configuração", e "tais descrições são" eminentemente "narrativas" (KRIEG, 1977, p. 195). Além disso, considerando que os atos de uma pessoa constituem, em grande medida, a realização de suas intenções, podemos dizer, nesses casos, "que ela revelou uma parte básica de si mesma em seu ato" (KRIEG, 1977, p. 193). Seguindo essa perspectiva, Krieg (1977, p. 199) comenta a posição barthiana de que a desconsideração das narrativas bíblicas na elaboração de uma compreensão acerca dos atributos de Deus representa, em última instância, um estudo de algo diferente da realidade divina. De acordo com essa posição, é 
inadequado explicar os atributos divinos utilizando como ponto de partida algo diferente das narrativas bíblicas que contam as ações de Deus.

Krieg (1977) apresenta dois exemplos do uso feito por Barth das narrativas bíblicas em seu desenvolvimento conceitual sobre a santidade de Deus: (1) o encontro de Deus com Moisés, retratado em Êxodo 3 e (2) o chamado de Isaías narrado em Isaías 6. Em ambas as narrativas encontramos o conceito de santidade (cf. Ex 3:5; Is 6:3) e a imagem de fogo queimando (cf. Êx 3:2; Is 6:6). No primeiro exemplo, Barth (2010, p. 366) ressalta que "a sarça ardente de Êx 3:2 não se consumia. Mas a sarça não consumida deveria queimar”. O teólogo suíço visualiza uma conexão da imagem do fogo dessa narrativa com a de Isaías 6, onde uma brasa viva do altar é usada para purificar os lábios de Isaías (Is 6:6-7). Embora Deus seja "fogo consumidor" (Dt 4:24; $\mathrm{Hb}$ 12:29), nas narrativas de Êxodo 3 e Isaías 6 o fogo queima, mas não consome. Assim, o conceito de santidade divina que Barth (2010, p. 363) desenvolve em diálogo com essas narrativas bíblicas é de que "a santidade de Deus consiste na unidade de Seu julgamento com Sua graça”. No caso de Isaías, o julgamento de sua impureza (cf. Is 6:4) ocorre graciosamente em termos de purificação e perdão (Is 6:7). Similarmente, na narrativa de Êxodo 3, a despeito de Barth e Krieg não desenvolverem esse ponto, o julgamento divino contra a opressão egípcia (cf. Êx 3:20) não significará a destruição conjunta dos israelitas, mas a libertação graciosa deles (cf. Exx 3:7-9, 12, 16-17).

Nesse ponto, é importante lembrar a noção de linguagem metafórica indicada por Ricoeur, que não expressa o seu referente em sua totalidade. Ao mesmo tempo que a imagem do fogo revela algo sobre Deus, a realidade divina completa lhe escapa. Contudo, a despeito desse jogo de velamento e desvelamento das imagens no discurso teológico, curiosamente as narrativas são capazes de fornecer maior especificidade pessoal aos conceitos do que o discurso especulativo abstrato. Nas palavras de Krieg (1977, p. 190), as narrativas "mostram o que não pode ser dito diretamente", proporcionando "um novo ângulo da realidade”. Krieg (1977) explica que esse princípio é ainda mais significativo quando buscamos compreender pessoas. Por exemplo, quando estamos conversando sobre um determinada indivíduo e, então, nosso interlocutor nos pergunta como essa pessoa é, podemos responder da seguinte forma: "Ela é sábia” ou "Ela é esnobe". Nessas declarações, chegamos praticamente no limite da descrição conceitual. Embora seja possível tentar especificar a sabedoria 
ou a arrogância do referido indivíduo a partir de outros conceitos, uma descrição que seja capaz de oferecer um nível mais apurado de especificidade acerca dessas declarações ("Ela é sábia” ou "Ela é esnobe”) precisará recorrer à narração de alguma ação realizada por essa pessoa em um determinado momento.

Se a existência pessoal tem caráter essencialmente narrativo, como já enfatizado acima, então a narrativa é o discurso privilegiado para a descrição concreta e mais específica de quem uma pessoa é. Desse modo, a reflexão teológica de Krieg indica que uma epistemologia narrativa abre possibilidades promissoras para nosso discurso acerca de Deus enquanto ser pessoal.

\section{CONSIDERAÇÕES FINAIS}

O presente artigo procurou discutir uma alternativa epistemológica para a teologia que não se caracterize pelo raciocínio metafísico abstrato da ontoteologia. A discussão dessa alternativa buscou observar possibilidades nos horizontes do pensamento narrativo. Após problematizar brevemente a crítica ao pensamento metafísico da ontoteologia em diálogo com Heidegger, este estudo buscou explorar as possibilidades epistemológicas oferecidas pelo pensamento narrativo, especialmente a partir das reflexões de Ricoeur. Por fim, a perspectiva ricoeuriana foi colocada em diálogo com uma reflexão teológica caracterizada por traços de uma epistemologia narrativa na teologia de Krieg.

Obviamente, na busca de horizontes epistemológicos para a teologia contemporânea, o diálogo com esses referenciais teóricos necessita ser aprofundado, como também incluir outros pensadores que colaborem para essa reflexão. Diante do questionamento, ainda em andamento, do pensamento metafísico, muito ainda deve ser pensado e empreendido em relação aos caminhos epistemológicos do labor teológico.

De qualquer modo, o presente estudo sugere que uma articulação epistemológica da teologia que privilegie o pensamento narrativo por meio da polifonia da linguagem bíblica, isto é, que leve em conta as perspectivas que emergem dos diferentes gêneros de discurso da literatura bíblica, se apresenta como um caminho bastante promissor para se pensar Deus. 


\section{REFERÊNCIAS}

AQUINO, Tomás. Suma Contra os Gentios. Trad. Odilão Moura e Ludgero Jaspers. Porto Alegre: Escola Superior de Teologia São Lourenço de Brindes, 1990.

AMBROSE, Glenn P. The Theology of Louis-Marie Chauvet: Overcoming OntoTheology with the Sacramental Tradition. New York: Routledge, 2016.

ASBILL, Brian D. The Freedom of God for Us: Karl Barth's Doctrine of Divine Aseity. London: Bloomsbury Academic, 2015.

BARTH, Karl. Church Dogmatics: The Doctrine of God. Vol. II, part I. Peabody, MA: Hendrickson Publishers, 2010.

BARTH, Karl. Dogmática Eclesiástica: Uma seleção com introdução de Helmut Gollwitzer. São Paulo: Fonte Editorial, 2017.

BIASOLI, Luís Fernando. Deus: Causa Sui: razão e transcendência nas meditações metafisicas de Descartes. Porto Alegre, 2011. Tese (doutorado) Pontifícia Universidade Católica do Rio Grande do Sul.

BOULNOIS, Olivier. When Does Ontotheology Begin? Aristotle, Thomas Aquinas, and Duns Scotus. In: Arc - The Journal of the School of Religious Studies, McGill University, vol. 44, p. 1-30, 2016.

CANALE, Fernando L. A Criticism of Theological Reason: Time and Timelessness as Primordial Presuppositions. Berrien Springs, MI: Andrews University Press, 1987.

DESCARTES, René. Oeuvres de Descartes. Editado por Charles Adam e Paul Tannery. Paris: Vrin/CNRC, 1971-1974, 13 v.

ELDERS, Leo J. The Philosophical Theology of St. Thomas Aquinas. Leiden: Brill, 1990.

FRAGOZO, Fernando. Heidegger e a metafísica como ontoteologia. In: Numen: revista de estudos e pesquisa da religião, vol. $9, \mathrm{n}^{0} 1$, p. 59-73, 2010.

GRENZ, Stanley J. The Named God and the Question of Being: A Trinitarian Theo-Ontology. Louisville, KY: Westminster John Knox Press, 2005.

HAHNENBERG, E. P. Awakening vocation: A Theology of Christian Call. Mahwah, NJ: Liturgical Press, 2010.

HEIDEGGER, Martin. A constituição onto-teo-lógica da metafísica. In: Conferências e Escritos Filosóficos. Trad. Ernildo Stein. São Paulo: Abril Cultural (Coleção Os Pensadores), 1973, p. 387-400. 
HEIDEGGER, Martin. Os conceitos fundamentais da metafísica: mundo, finitude, solidão. $2^{\mathrm{a}}$ ed. Rio de Janeiro: Forense Universitária, 2011.

HEIDEGGER, Martin. O princípio do fundamento. Lisboa: Instituto Piaget, 2000.

KRIEG, Robert A. Narrative as a Linguistic Rule: Fyodor Dostoyevsky and Karl Barth. In: International Journal for Philosophy of Religion, vol. 8, no 3, p. 190-205, 1977.

KRIEG, R. A. Story-shaped Christology: The Role of Narratives in Identifying Jesus Christ. Mahwah, NJ: Paulist Press, 1988.

KRIEG, R. A. The Theologian as Narrator: A Study of Karl Barth on the Divine Perfections. Notre Dame, IN, 1978. Tese (Doutorado em Teologia) - University of Notre Dame.

KRIEG, R. A. Treasure in the Field: Salvation in the Bible and in Our Lives. Collegeville, MN: Liturgical Press, 2013.

KÜNG, Hans. Does God Exist: An Answer for Today. Trad. Edward Quinn. New York: Vintage Books, 1981.

LEE Jr., Richard A. The Scholastic Resources for Descarte's Concept of God as Causa Sui. In: GARBER, Daniel; NADLER, Steven (orgs.). Oxford Studies in Early Modern Philosophy. v. 3. Oxford: Clarendon Press; Oxford University Press, 2006, p. 91-118.

LEITE, Rondnelly Diniz. A crítica à noção de Deus própria da constituição onto-teo-lógica da metafísica tradicional em Martin Heidegger. Belo Horizonte, 2012. Dissertação (mestrado) - Faculdade Jesuíta de Filosofia e Teologia.

LUCIE-SMITH, A. Narrative Theology and Moral Theology: The Infinite Horizon. New York: Routledge, 2016.

MARION, Jean-Luc. Dieu sans l'être. $4^{\mathrm{a}}$ ed. Paris: Presses Universitaires de France, 2013.

MARION, Jean-Luc. God without Being: Hors Texte. Chicago: University of Chicago Press, 1995.

MARION, Jean-Luc. Thomas Aquinas and Onto-theo-logy. In: KESSLER, Michael; SHEPPARD, Christian (orgs.). Mystics: Presence and Aporia. Chicago; London: The University of Chicago Press, 2003, p. 38-74.

MARTINI, Rosa Maria Filippozzi. Paul Ricoeur: metáfora e metafísica. In: Filosofia Unisinos, vol. 15, $\mathrm{n}^{\mathrm{o}}$ 3, p. 210-225, 2014. 
METTINGER, Tryggve N. D. O significado e a mensagem dos nomes de Deus na Bíblia. Santo André, SP: Academia Cristã, 2008.

MOLTMANN, Jürgen. The Crucified God: The Cross of Christ as the Foundation and Criticismo f Christian Theology. Trad. R. A. Wilson e John Bowden. Minneapolis, MN: Fortress Press, 1993.

NIETZSCHE, Friedrich. A gaia ciência. São Paulo: Editora Escala, 2006.

NIETZSCHE, Friedrich. Além do bem e do mal: prelúdio a uma filosofia do futuro. $2^{a}$ ed. Trad. Paulo César de Sousa. São Paulo: Companhia das Letras, 1992.

NIETZSCHE, Friedrich. Assim falou Zaratustra: um livro para todos e para ninguém. Trad. Carlos Duarte e Anna Duarte. São Paulo: Martin Claret, 2014.

PENZO, Giorgio. Friedrich Nietzsche (1844-1900): O divino como problematicidade. In: PENZO, Giorgio; GIBELLINI, Rosino (orgs.). Deus na filosofia do século XX. $3^{\mathrm{a}}$ ed. São Paulo: Edições Loyola, 2002, p. 23-35.

RICOEUR, Paul. A Hermenêutica Bíblica. São Paulo: Edições Loyola, 2017.

RICOEUR, Paul. Entre filosofia e teologia II: nomear Deus (1977). In: Leituras 3: nas fronteiras da filosofia. Trad. Nicolás Nyimi Campanário. São Paulo: Edições Loyola, 1996, p. 181-204.

RICOEUR, Paul. Pensando Biblicamente. Trad. Raul Fiker. Bauru, SP: EDUSC, 2001.

SCHRIJVERS, Joeri. Marion, Levinas, and Heidegger on the Question Concerning Ontotheology. In: Continental Philosophy Review, vol. 43, n. 2, p. 207-39, 2010.

SOUSA, Mauro Araujo. A morte de Deus em Nietzsche: fim da metafísica. In: MARASCHIN, Jaci; PIRES, Frederico Pieper (orgs.). Teologia e PósModernidade: ensaios de teologia e filosofia da religião. São Paulo: Fonte Editorial, 2008, p. 62-90.

SOUZA, Vitor Chaves de. Uma teologia do nome divino em Paul Ricoeur. In: Notandum, vol. 33, p. 59-70, set./dez., 2013.

SOUZA, Vitor Chaves de. A dobra da religião em Paul Ricoeur. Santo André, SP: Editora Kapenke, 2017.

THOMSON, Iain. Heidegger on Ontotheology: Technology and the Politics of Education. New York: Cambridge University Press, 2005.

THOMSON, Iain. Ontotheology? Understanding Heidegger's Destruktion of Metaphysics. In: International Journal of Philosophical Studies, vol. 8, $\mathrm{n}^{\mathrm{0}} 3$, p. 297-327, 2000. 
VANHOOZER, Kevin J. Remythologizing Theology: Divine Action, Passion, and Authorship. New York: Cambridge University Press, 2010.

WESTPHAL, Meorld. Overcoming Onto-Theology: Toward a Postmodern Christian Faith. New York: Fordham University Press, 2001.

Recebido em: 27.09.2018 Aprovado em: 24.12.2018 